\title{
Growing role of walking and cycling and the associated risks
}

\author{
Romanika Okraszewska ${ }^{1, *}$, Krystian Birr ${ }^{1}$, Lucyna Gumińska ${ }^{1}$, and Lech Michalski ${ }^{1}$ \\ ${ }^{1}$ Gdansk University of Technology, Faculty of Civil and Environmental Engineering, Gdansk, Poland
}

\begin{abstract}
Increasing the role of active mobility, including walking and cycling, is one of the tools for developing sustainable urban transport systems as recommended by the EU. The article describes the trends in pedestrian and bicycle traffic in Poland and its share in urban modal split. It identifies and describes the main sources of risks to pedestrian and cycle safety. Recommendations are proposed on how to ensure that pedestrians and cyclists can use traffic safely.
\end{abstract}

\section{Introduction}

Tackling climate change is one of the biggest challenges for international cooperation [1]. It is largely influenced by transport which represents a major and increasingly big source of greenhouse gas emissions [2]. Urban traffic accounts for $40 \%$ of $\mathrm{CO}_{2}$ emissions and $70 \%$ of other road transport-related emissions [3]. In a bid to tackle climate change the European Commission has set emission targets. They are to reduce greenhouse gas emissions by 2050 by at least $60 \%$ compared to 1990 levels [4]. As regards transport, the European Commission believes that the targets can be achieved through progress in technology and/or change in how the public use transport, i.e. by reducing car trips in favour of public transport and choosing active forms of mobility such as walking and cycling [5]. If we could increase the share of walking and cycling in the modal split by reducing car trips, we could also reduce congestion which affects all of Poland's major cities and people's quality of life. Active forms of mobility are also good for those walking or cycling and they have an indirect positive effect on the health of everyone else [6]. Apart from those health benefits, nonmotorised forms of transport also offer environmental, economic, social and spatial benefits. This is why many cities in the world and in Poland have policies designed to increase the share of active forms of mobility in how people travel [5]. Because urban and rural walking and cycling differ, this article covers built-up areas only. It gives an overview of the trends and the changing role of pedestrian and cycle traffic in Poland's built-up areas between 2009 and 2016. As well as identifying the risks to pedestrians and cyclists, the article uses international experience and available cyclist and pedestrian accident data to discuss the relation between the safety of vulnerable road users and the volume of pedestrian and cycle traffic.

* Corresponding author: rokrasze@.pg.gda.pl 


\section{Trends in pedestrian and cycle traffic}

Walking is the oldest form of transport. Today, walking is usually used for short trips. Up to $60 \%$ of trips up to 2 kilometres are made on foot and as many as $80 \%$ for trips up to 1 kilometre. Studies of transport behaviour conducted in Poland show that walking accounts for $10-29 \%$ (Table 1) of all urban trips. In some European cities such as Lyon (France), Oslo (Norway), Helsinki (Finland) and Valencia (Spain) walking has a share of more than $30 \%$ [6]. The studies also established that cycle trips differ from city to city and range between $1 \%$ to $10 \%$ of all urban trips (Table ).

Table 1. Modal split in selected Polish cities. Source: [6].

\begin{tabular}{|c|c|c|c|c|c|}
\hline City & Year & Walking & Cycling & Private transport & Public transport \\
\hline Chorzów & 2011 & $11 \%$ & $10 \%$ & $56 \%$ & $23 \%$ \\
\hline Gdańsk & 2016 & $21 \%$ & $6 \%$ & $41 \%$ & $32 \%$ \\
\hline Poznań & 2013 & $13 \%$ & $4 \%$ & $39 \%$ & $43 \%$ \\
\hline Wrocław & 2011 & $19 \%$ & $4 \%$ & $42 \%$ & $35 \%$ \\
\hline Płock & 2015 & $10 \%$ & $2 \%$ & $53 \%$ & $35 \%$ \\
\hline Kraków & 2013 & $29 \%$ & $1 \%$ & $27 \%$ & $43 \%$ \\
\hline Szczecin & 2010 & $19 \%$ & $1 \%$ & $43 \%$ & $35 \%$ \\
\hline Warsaw & 2010 & $21 \%$ & $1 \%$ & $24 \%$ & $54 \%$ \\
\hline Kraków & 2010 & $25 \%$ & $1 \%$ & $28 \%$ & $46 \%$ \\
\hline
\end{tabular}

As we can see in Table 2 cycling has been growing annually whilst walking maintains a fairly constant share in the modal split in Polish cities. Analysis of the change in the modal split suggests that a large part of cyclists give up their daily trips by public transport. In the last seven years Gdansk's cycle traffic has grown by 4 percentage points whilst the share of public transport dropped by 6 percentage points $[7,8]$.

Table 2. Change in cycling and walking within the modal split of selected Polish cities. Source: [7-12].

\begin{tabular}{|c|c|c|c|c|}
\hline \multirow{2}{*}{ City } & \multicolumn{2}{|c|}{ Trips } & \multicolumn{2}{|c|}{ Trips } \\
\hline & Walking & Cycling & Walking & Cycling \\
\hline \multirow{2}{*}{ Cracow } & \multicolumn{2}{|c|}{2003} & \multicolumn{2}{|c|}{2013} \\
\hline & $29 \%$ & $1 \%$ & $30 \%$ & $2 \%$ \\
\hline \multirow{2}{*}{ Warsaw } & \multicolumn{2}{|c|}{2005} & \multicolumn{2}{|c|}{2016} \\
\hline & $21 \%$ & $1 \%$ & $18 \%$ & $3 \%$ \\
\hline \multirow{2}{*}{ Gdansk } & \multicolumn{2}{|c|}{2009} & \multicolumn{2}{|c|}{2016} \\
\hline & $21 \%$ & $2 \%$ & $21 \%$ & $6 \%$ \\
\hline
\end{tabular}

Depending on the methodology, transport behaviour studies define travelling on foot as trips not shorter than e.g. $250 \mathrm{~m}[9,10,13]$. When treated as an element of public transport trips, walking and cycling are interpreted differently depending on the methodology.

Designed to increase active mobility and reduce motor traffic, many strategies for sustainable transport foster cycling and walking by curbing car space. This includes limiting parking 
space, introducing traffic restrictions and traffic calming and banning cars entirely from specific streets. Another objective is to develop pedestrian and cyclist infrastructure. Warsaw's total length of cycle routes is $457 \mathrm{~km}, 219 \mathrm{~km}$ in Gdansk, $165 \mathrm{~km}$ in Krakow, 164 $\mathrm{km}$ in Łódź, $107 \mathrm{~km}$ in Białystok and $30 \mathrm{~km}$ in Słupsk. If we consider the relation between the length of cycle routes $[\mathrm{km}]$ and the size of the city $\left[\mathrm{km}^{2}\right]$, Białystok comes up first with a rate of 1.05 , followed by Warsaw at 0.88 , Gdansk at 0.84 , Słupsk at 0.70 , Krakow at 0.50 and Łódź at 0.49 .

Due to the scale of change in cycle traffic, the growth can be seen not only in the statistics but on the streets as well. The growing significance of cycling as part of the modal split is accompanied by an increase in cyclists. As an example, Gdansk monitors cycle traffic on specific cross-sections using automatic counters [14] (Fig. 1). There are also regular manual counts conducted by the staff of the Gdansk Development Agency [15].

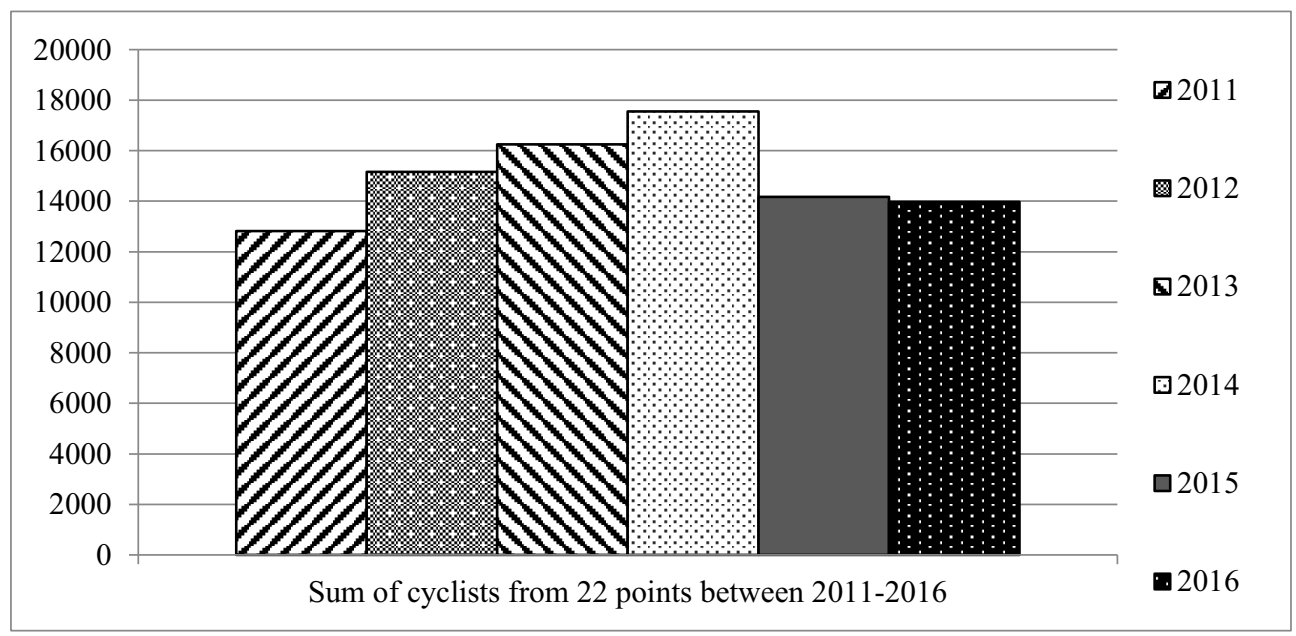

Fig. 1. Sum of cyclists recorded between 2011-2016 by automatic traffic counters on 22 crosssections. Source: own work based on [14].

The results of automatic and manual counts are consistent and show an upward trend in cyclists. In 2015 the number of cyclists dropped on the analysed cross-sections while cycling gained a higher share in the modal split. This could be a consequence of new cycling infrastructure projects leading to a more dispersed cycle traffic on the growing network of cycle routes.

\section{Road safety level}

The change in pedestrian and cycle traffic affects the safety of vulnerable road users. Overall, Poland's road safety has improved significantly over the last five years (Fig.3). In 2015 compared to 2010 road accidents dropped by $15 \%$ (5 865 accidents), casualties went down by $19 \%$ (9 174 people) with fatalities decreasing by as much as $25 \%$ (970 people). Pedestrian safety has improved as well. Pedestrian accidents in the last five years dropped by nearly $24 \%$ with fatalities down by $26 \%$. Cycle accidents, on the other hand, are on the rise. In 2015 compared to 2010 cyclist accidents went up by $18.3 \%$, casualties by nearly $17 \%$ and fatalities increased by $7 \%$. 


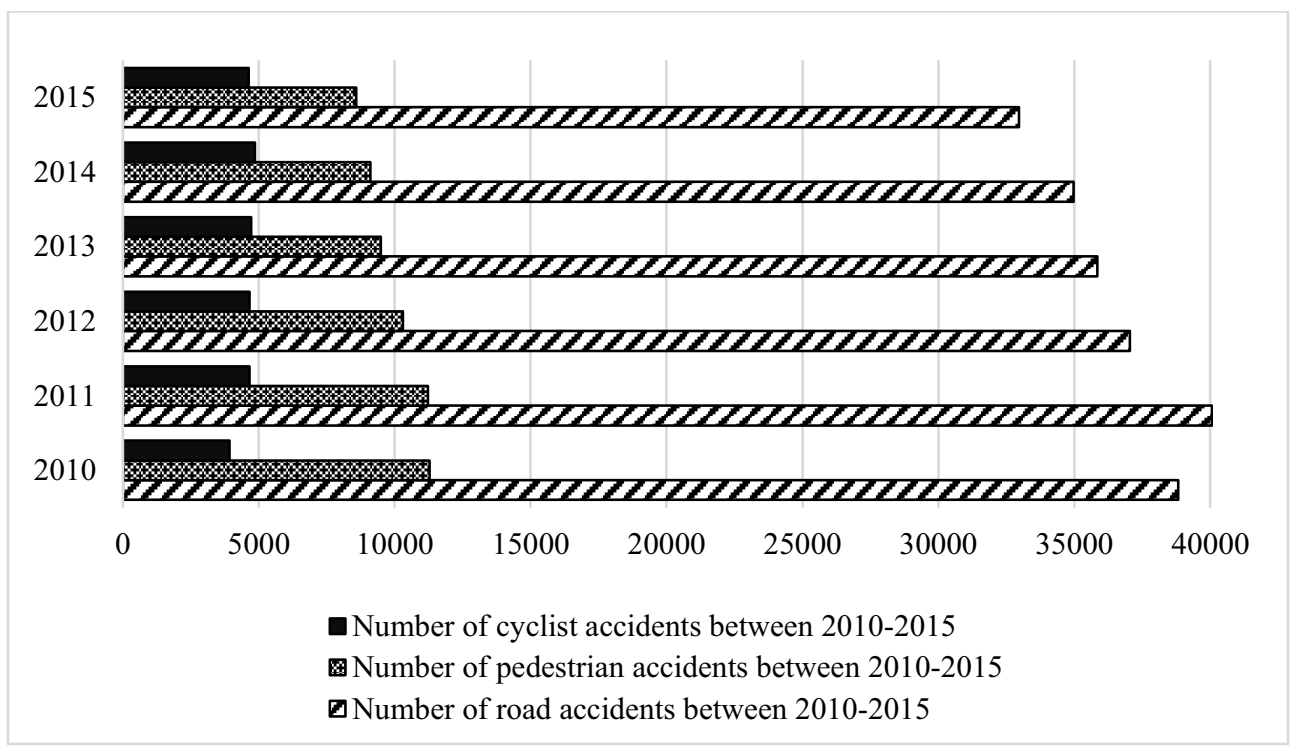

Fig. 2. Number of accidents by type of casualties. Source: own work based on National Police annual reports $2010-2015$.

The risks to pedestrian traffic can be divided into groups involving:

- dangerous driver behaviour that may lead to a pedestrian accident (i.e. failure to give way, driving too fast, running the red light),

- dangerous pedestrian behaviour (i.e. stepping onto the road suddenly, using the wrong side of the road if there is no pedestrian infrastructure),

- poor pedestrian infrastructure (i.e. no pedestrian pavements, narrow pavements, obstacles on pavements, poor lighting of pedestrian facilities, conflicts with cyclists),

- faulty pedestrian facilities (i.e. pedestrian crossings located in front of bus bays, no pavements).

Pedestrian risks are covered in detail in the manual for pedestrian traffic designers titled "Pedestrian Safety" [16]. The book presents methods for assessing pedestrian risks and proposed pedestrian safety measures.

Safety is a key factor when deciding to use the cycle as a means of transport. Unless cyclists feel safe, they are less likely to use the cycle as a means of transport. Police reports provide cycle accident statistics. They can be used to understand the conditions and circumstances that determine cycle safety. The factors identified in the reports can be grouped into main categories which involve:

- external conditions (time and circumstances of the accident, time of day, lighting, cyclists using lights and reflectors, the weather),

- the behaviour of road users,

- infrastructure and layout.

The majority of cycle accidents:

- occur in daylight and do not involve alcohol,

- involve side crashes, followed by rear and head-on collisions,

- involve cars, followed by lorries;

- occur when cyclists or drivers fail to give way, when drivers overtake illegally and cyclists turn illegally.

Police statistics shows that drivers and cyclists take equal blame for accidents. The most frequent cause is wrong behaviour by one of the road users. Drivers will usually fail to give way, overtake and turn illegally, go too fast for the conditions, bypass illegally and do not 
keep the right clearance. Cyclists, on the other hand, cause accidents by riding on the wrong side of the road and riding across pedestrian crossings illegally [16]. The age distribution of cyclists involved in accidents shows that accidents most often involve young cyclists aged 11-19 and those aged 50 to 59 .

\section{The level of risk to pedestrians and cyclists in Poland}

The level of cycle and pedestrian traffic safety is determined depending on:

- the area (e.g. number of fatalities per one million kilometres),

- demographics (e.g. share of pedestrians/cyclists in total road accident fatalities or the number of pedestrian and cyclist fatalities per one million population),

- transport (number of fatalities in cyclist accidents per $100 \mathrm{~km}$ of cycling).

For a number of years Poland has been the European Union's worst country for pedestrian safety Fig. 3 and cyclist safety Fig. 4 in road traffic.

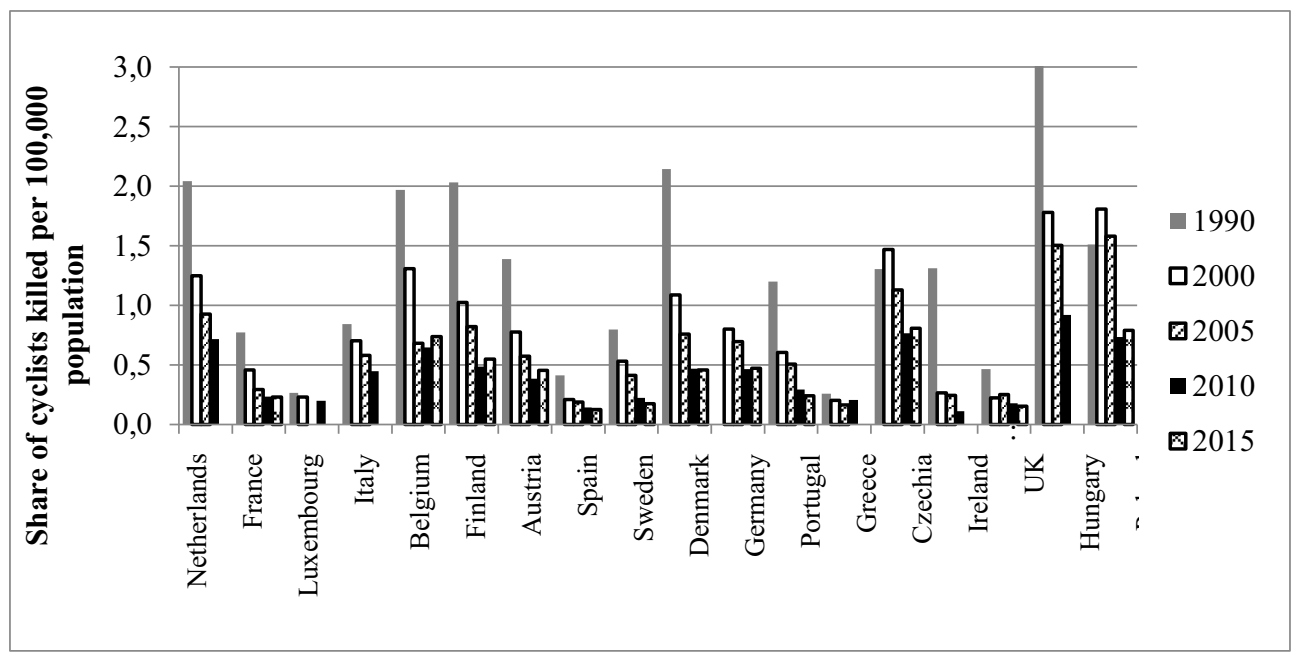

Fig. 3. Share of cyclists killed per 100000 population. Source: own work based on [17].

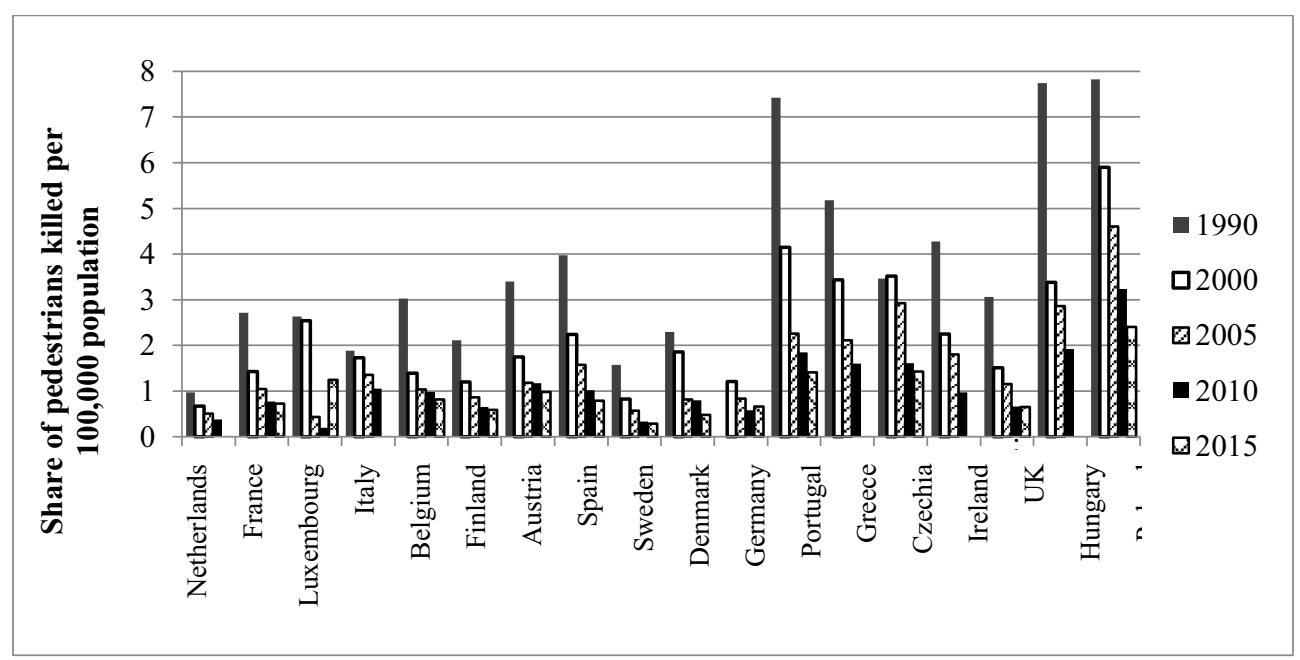

Fig. 4. Share of pedestrians killed per 100000 population. Source: own work based on [17]. 
The country's pedestrian and cyclist safety rates vary across the country and depend on the administrative area's characteristics. They also depend on the degree of urbanisation. Built-up and non-built-up areas have different pedestrian and cyclist safety rates [19]. While the majority of pedestrian and cyclist accidents occur in built-up areas, the consequences of rural accidents are much more severe. In 2015 there was one pedestrian fatality in every third accident in a non-built-up area and one cyclist fatality in every fifth compared to one pedestrian fatality in every thirteenth accident in a built-up area and one cyclist fatality in every twentieth accident [20].

However, none of these rates give a realistic measure of cycling safety or directly show the risk of an accident when cycling or walking. The number of pedestrian and cyclist accidents which is the basis for calculating all rates, depends on a number of factors $[16,17]$ including traffic volume. Using statistics from US cities P.L. Jacobsen expressed the relation between the number of accidents and how big cycle traffic is using this formula [21]:

$$
\text { Number of cyclist accidents }=\text { cycle traffic volume }{ }^{0,4}
$$

The share of cycling in Poland is still low. The authors of the Strategy for Transport and Mobility in Gdansk's Metropolitan Area studied the relation between the number of cyclist accidents and the low share of cycling in overall trips. The results show that cycling carries the highest risk [22].

\section{Conclusions}

The role of walking and cycling as part of urban transport services is growing. This is the result of efforts to promote cycling, foster public transport and limit car use.

Over the last five years Poland's pedestrian safety has improved. The number of pedestrian accidents dropped by nearly $24 \%$ and the number of killed went down by $26 \%$. Despite that in Poland every third road fatality is a pedestrian compared to the EU's every fifth. This is the result of driver behaviour and condition of pedestrian facilities.

Over the same period the number of cyclist accidents went up by $18.3 \%$, the number of casualties rising by nearly $17 \%$ and fatalities by $7 \%$. Forecasts show that cyclist accidents will continue to increase. This is due to growing cycling traffic, driver and cyclist behaviour, the safety standards of cycle infrastructure and how cycle traffic is organised.

The road safety system today still fails to provide an effective way to protect pedestrians and cyclists from injury or death. While cities are building cycle infrastructure, it is not available outside them. The new infrastructure does not come with campaigns to promote safe behaviour mainly that of cyclists using road traffic.

\section{Systemic solutions to improve pedestrian and cyclist safety}

To address the challenges of growing cycle trips and the potential increase in cyclist accidents, actions are needed to reduce the impacts as much as possible. This should include a consistent and easy to use network of cycle routes. Building new cycle routes or designating cycle lanes is not enough because more needs to be done to adjust the infrastructure, organise cycle traffic and put up clear signage to mark the beginning and end of cycle routes. It is vital to educate and promote safe behaviour. Cyclists are not legally required to hold a driving license. While they are expected to know traffic regulations and follow them, practice shows that this is not always the case. 


\section{References}

1. European Commission, Communication from the Commission to the European Parliament, the Council, the European Economic and Social Committee and the Committee of the Regions on a roadmap for moving to a competitive low carbon economy in 2050, $\mathrm{COM}(2011) 112$ (Brussels, 2011)

2. European Commission, White Paper "Roadmap to a Single European Transport Area Towards a competitive and resource efficient transport system". COM(2011) 144 final (Brussels, 2011)

3. European Commission, Green Paper "Towards a new culture for urban mobility", COM (2007) 551 (Brussels, 2007)

4. S.A. Goldsmith, Reasons why bicycling and walking are and are not being used more extensively as travel modes (Federal Highway Administration, 1992)

5. R. Okraszewska, Z. Jagielska, Comparison of Polish and Danish approach to promotion of cycling, (2017)

6. TEMS - The EPOMM Modal Split Tool, available at: http://epomm.eu/tems/index.phtml?Main_ID=2928, (2016)

7. Comprehensive Traffic Research Gdansk (in Polish) (Gdansk Development Office, Gdansk, 2009)

8. Gdansk Traffic Research. A Leaflet (in Polish) (VIA VISTULA, Gdansk, 2016)

9. Comprehensive Traffic Research Cracow (in Polish) (Cracow, 2003)

10. Comprehensive Traffic Research Cracow (in Polish) (Cracow, 2013)

11. Comprehensive Traffic Research Warsaw (in Polish) (Warsaw, 2005)

12. Warsaw Traffic Research (in Polish) (Warsaw, 2015)

13. G. Sierpiński, M. Staniek, I. Celiński, P. Czech, J. Barcik, Identification of pedestrian travel in modeling of modal split and transport accessibility, Logistyka. 4 (2015)

14. Points of measurement of cycling traffic - Bicycle Gdansk' (in Polish), available at: http://rowerowygdansk.pl/start,169,170.html, (2017)

15. The comparison of cyclists measurement in 2011-2014 (in Polish) (Gdansk Development Office, Gdansk, 2014)

16. K. Jamroz, S. Gaca, L. Michalski, M. Kieć, M. Budzyński, L. Gumińska, W. Kustra, T. Mackun, I. Oskarbska, J. Rychlewska, A. Ryś, J. Wachnicka, J. Wierzbicka, Protection of Pedestrians. Guidelines for pedestrian traffic organizers (in Polish) (National Road Safety Council, Gdansk, Warsaw, Cracow, 2014)

17. A. Buczyński, Traffic incidents involving cyclists 2006-2008' (in Polish) (Cracow, Poland, 2009)

18. OECD Statistics, available at: http://stats.oecd.org/, (2017)

19. R. Okraszewska, K. Jamroz, M. Bauer, K. Birr, A. Gobis, Identification of risk factors for collisions involving cyclists based on Gdansk example, (2017)

20. E. Symon, Road accidents in Poland in 2015. Report of General Police Headquarters of Poland (Warsaw, 2016)

21. P.L. Jacobsen, Safety in numbers: more walkers and bicyclists, safer walking and bicycling, Inj. Prev. 9 pp. 205-209 (2003). doi:10.1136/ip.9.3.205

22. L. Michalski, K. Jamroz, K. Grzelec, S. Grulkowski, D. Kaszubowski, R. Okraszewska, K. Birr, W. Kustra, Strategy of Transport and Mobility for Metropolitan Area (in Polish) (Gdansk Metropolitan Area, Gdansk, 2015) 